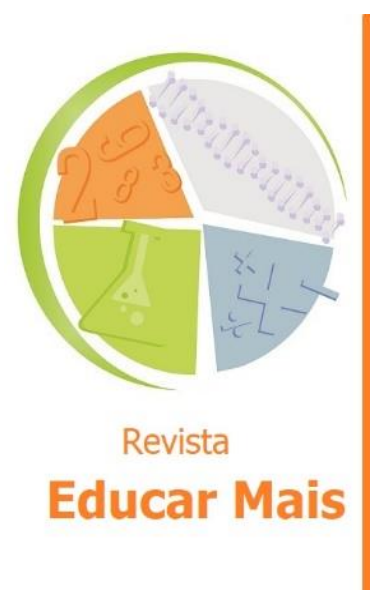

\title{
Análise quantitativa dos graduados, acadêmicos e evadidos do curso de Licenciatura em Física da UFAC: um diagnóstico inicial
}

\author{
Quantitative analysis of graduates, academics and evaded from course \\ of Physics of UFAC: an initial diagnosis
}

\section{Análisis cuantitativo de egresados, académicos y desertores de la carrera de Física de la UFAC: un diagnóstico inicial}

Bianca Martins Santos ${ }^{1}$; Marcelo Castanheira da Silva ${ }^{2}$; Antonio Romero da Costa Pinheiro $^{3}$; Irlen Maycon Pereira da Silva Paiva ${ }^{4}$; Eloi Benicio de Melo Junior ${ }^{5}$

\begin{abstract}
RESUMO
O presente trabalho visa apresentar um diagnóstico inicial sobre o quantitativo de alunos que evadiram e concluíram o curso de licenciatura em Física da Universidade Federal do Acre. O estudo foi baseado nos dados fornecidos pela coordenação do curso referente aos treze anos de existência, a partir da abertura em 2005 até o primeiro semestre de 2018. O estudo ainda apresenta abordagem estatística e uma reflexão sobre a importância do curso para o estado do Acre, bem como apresenta elementos do perfil do licenciado em Física (diplomado), como sexo, idade que concluiu a graduação, naturalidade e tempo necessário para integralizar os estudos. Verificou que a diferença de sexo, forma de ingresso e períodos cursados estão ligados à evasão dos graduandos. Constatou-se que os $4^{\circ}$ e $6^{\circ}$ períodos têm o maior índice de evasão, a formação por outro lado ocorre entre o $8^{\circ}$ e $11^{\circ}$ período.
\end{abstract}

Palavras-chave: Formação de professores; Evasão; Licenciatura em Física.

\section{ABSTRACT}

The present work aims to present an initial diagnosis on the number of students who escaped and completed the Physics degree course at the Federal University of Acre. The study was based on the course coordinator's data for the thirteen years of existence, 2005 - 2018. It presents a statistical approach and a reflection on the importance of the course for Acre's state; presents elements of the Physics graduate, such as sex, age at graduation, the place of birth, and the time required to complete the studies. It found that the difference in sex, form of admission, and periods of study are linked to dropout rates. It was found that the 4th and 6th

\footnotetext{
1 Professora da Universidade Federal do Acre (UFAC) com Pós-Doutorado, Doutorado e Mestrado em Física. É coordenadora do programa de pós-graduação do Mestrado Nacional Profissional em Ensino de Física (MNPEF/ Polo 59) e docente vinculada ao Mestrado Profissional em Ensino de Ciências e Matemática (MPECIM). E-mail: bianca8ms@gmail.com

2 Professor da Universidade Federal do Acre (UFAC) com Doutorado e Mestrado em Física. Professor do Mestrado Nacional Profissional em Ensino de Física (MNPEF - polo 59) e do Mestrado Profissional em Ensino de Ciências e Matemática (MPECIM). Vice-coordenador do curso de Licenciatura em Física. Vice-coordenador da Estação de Geofísica Aplicada do Acre credenciada a Agência Nacional do Petróleo, Gás Natural e Biocombustíveis (ANP). E-mail: mar_castanheira@yahoo.com.br

3 Professor da Universidade Federal do Acre (UFAC) com Doutorado e Mestrado em Física. E-mail: aromerocp@gmail.com

${ }^{4}$ Graduação em Ciências Sociais e secretário do curso de Licenciatura em Física. Bacharel em Ciências Sociais. E-mail: irlen.maycon.pereira@gmail.com

${ }^{5}$ Doutorando em Física no Centro Brasileiro de Pesquisas Físicas (CBPF) com Mestrado em Física. E-mail: eloibmj@gmail.com
} 
periods have the highest dropout rate. The formation, on the other hand, occurs between the 8th and 11th period.

Keywords: Teacher training. Dropout. Degree in physics.

\section{RESUMEN}

El presente trabajo tiene como objetivo presentar un diagnóstico inicial sobre el número de estudiantes que escaparon y completaron la carrera de Física en la Universidad Federal de Acre. El estudio se basó en datos proporcionados por el coordinador del curso durante los trece años de existencia, desde la apertura en 2005 hasta el primer semestre de 2018. El estudio aún presenta un enfoque estadístico y una reflexión sobre la importancia del curso para el estado de Acre. Así como presentar elementos del perfil del egresado de Física, como el sexo, la edad que completó la graduación, el lugar de nacimiento y el tiempo requerido para completar los estudios. Encontró que la diferencia en el sexo, la forma de admisión y los períodos de estudio están vinculados a las tasas de abandono. Se encontró que los períodos 4 y 6 tienen la mayor tasa de deserción, la formación por otro lado ocurre entre el período 8 y 11.

Palabras clave: Formación de profesores; Evasión; Grado en Física.

\section{INTRODUÇÃO}

A Universidade Federal do Acre (UFAC) foi criada em 25 de março de 1964 (Decreto Estadual no 187), tendo como primeiro curso, a Faculdade de Direito. Em 1970 foi criado o segundo curso, a Faculdade de Ciências Econômicas, e, nesse mesmo ano, a implantação dos cursos de licenciatura em Letras, Pedagogia, Matemática e Estudos Sociais. Com isso foi possível oficializar, em 03 de março de 1970, o Centro Universitário do Acre. Em 22 de novembro de 1971 transformou-se em Universidade Federal do Acre, sob o regime de fundação, e federalizou-se em 1974, através da Lei 6.025, de abril de 1974, e Decreto no. 74.706, de outubro de 1974 (UFAC, 2011).

A UFAC foi por muito tempo, desde 1964, a única instituição pública e gratuita de ensino superior no estado do Acre. O Instituto Federal de Educação, Ciência e Tecnologia do Acre (IFAC) foi legalizado em 29 de dezembro de 2008, Lei 11.892, e somente em 17 de dezembro de 2009 teve o primeiro reitor pro tempore nomeado (IFAC, 2016).

Em 1976 a UFAC instituiu a Licenciatura Curta em Ciências com habilitação em Física, Química e Biologia. A partir de 1990 iniciou a dissolução do citado curso com a criação da Licenciatura Plena em Ciências Biológicas, seguida pelas áreas de Física e Química em 1995. O Projeto Pedagógico Curricular (PPC 2005) da Licenciatura Plena em Física tinha 3.275 horas. Uma nova versão do PPC foi implantada em outubro de 2010, com 2.810 horas, devido à necessidade de incluir Libras e outras disciplinas, bem como rearranjos na organização do currículo.

Como foi dito, a Licenciatura em Física na UFAC iniciou suas atividades em 2005, embora a habilitação nessa área, proporcionada pela Licenciatura Curta em Ciências, já acontecia desde 1976. Esse fato consagrou a UFAC como sendo a primeira instituição pública a ofertar essa modalidade de curso no estado. O IFAC inaugurou o primeiro curso de Licenciatura em Física em 2011, no Campus Sena Madureira (IFAC, 2009), e o segundo em 2015 no Campus Cruzeiro do Sul (IFAC, 2014).

É importante destacar que o principal destino de mercado de trabalho do professor de Física, egresso do curso de Física da UFAC, é a função de docente na Educação Básica do estado do Acre (pública e/ou privada), muito embora lecionem em faculdades particulares, onde geralmente é exigido pelo 
menos um curso de especialização. Também podem atuar em oportunidades de trabalho em instituições de ensino públicas, quando há dificuldade de preenchimento de vagas para doutor ou mestre, abrem-se inscrição de apenas graduado, fato decorrentes geralmente nos concursos públicos para professores nos Institutos Federais como o IFAC, que no curso de Licenciatura em Física tem no quadro docente egressos do curso de Licenciatura da UFAC, fato que destaca a contribuição e importância desta para o Estado. Embora o mercado de trabalho para professores da educação básica necessite de mão de obra, as condições de trabalho e salariais não costumam ser satisfatórias, principalmente as oferecidas pelas escolas públicas. Esta situação pode provocar a migração de licenciados para outros empregos ou campos de atuação.

O Censo Escolar da Educação Básica realizado pelo Instituto Nacional de Estudos e Pesquisas Educacionais Anísio Teixeira (INEP), ano base 2016 (INEP, 2017a, p. 28), aponta que apenas 41,4\% dos docentes de Física do ensino médio têm formação adequada, ou seja, aqueles professores com formação superior de licenciatura (ou bacharelado com complementação pedagógica) na mesma área da disciplina que leciona. A situação para o estado do Acre quanto a relação entre docentes em exercício versus área de formação está longe da ideal, não só para a disciplina de Física, mas para todas as componentes curriculares do ensino médio. Na Figura 1(a), estão apresentados os resultados, segundo o documento citado, sobre a distribuição percentual média dos professores com formação adequada por município do estado do Acre, no qual é possível verificar que apenas a parte do mapa em destaque na cor verde, a capital Rio Branco, apresenta o percentual médio entre 55,1\% e $75 \%$ do total de professores em exercício são formados na mesma área de atuação no ano de 2016. Já no censo de 2018 esta realidade não mudou muito, este percentual ficou entre 60,1\% e $80,0 \%$ para capital (Figura 1(b)). Observa-se que a situação no interior do estado se agrava. Neste sentido, os cursos de licenciatura existentes no estado estabelecem papel fundamental para suprir tal carência.

Figura 1: Percentual de disciplinas que são ministradas por professores com formação adequada no ensino médio por município em 2016 (a) e em 2018 (b). São apresentados apenas o recorte dos resultados referente ao estado do Acre.

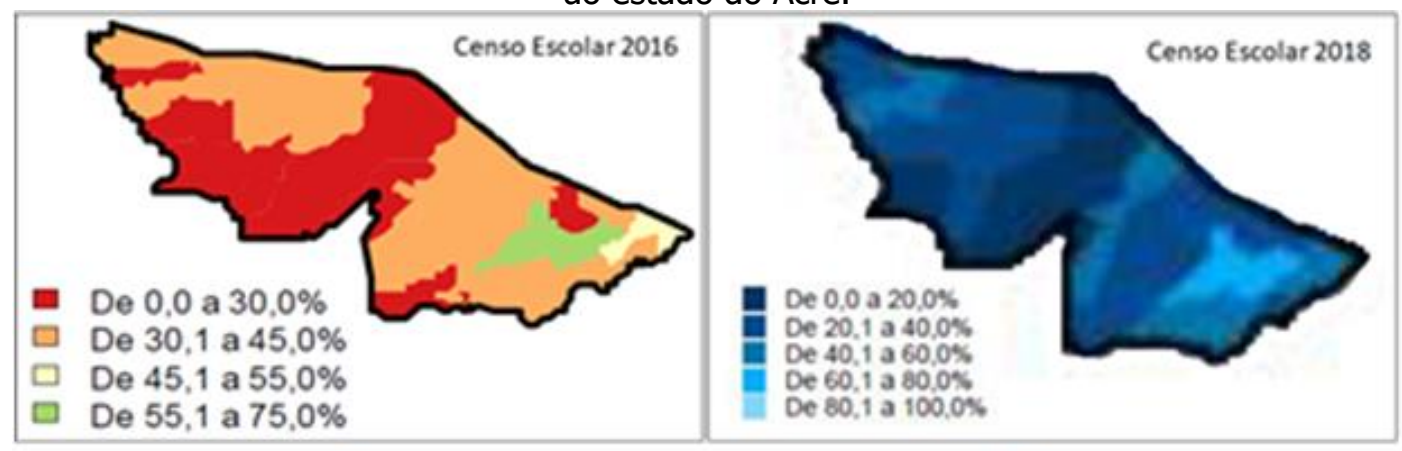

(a)

(b)

Fonte: (a) INEP, 2017a, p. 28; (b) INEP, 2019, p. 5.

Frequentemente o governo federal, através do Ministério de Educação (MEC), tem buscado incentivar a formação e capacitação de professores. O MEC lançou em outubro de 2017 a Política Nacional de Formação de Professores (PNFP) (MEC, 2018), cuja meta é ampliar a qualidade e o acesso à formação inicial e continuada desses profissionais na educação básica. O Programa de Residência Pedagógica, uma das ações da PNFP, faz parte da modernização do Programa Institucional de Bolsas de Iniciação à Docência (PIBID) e atuará por meio de estágio supervisionado, cujo foco é a melhoria da qualidade de formação inicial dos graduandos das licenciaturas. 
Neste cenário, a formação de professores para atuar na educação básica é evidenciado. Entretanto, muitos cursos de licenciatura, inclusive em Física, apresentam altos índices de evasão. Pereira de Ataíde, Lima e Alves (2006), ao analisarem a repetência e/ou abandono escolar no curso de Licenciatura em Física no ano letivo de 2005 da Universidade Estadual da Paraíba (UEPB), identificaram em entrevistas diversos motivos para justificar a interrupção do transcorrer normal de seus estudos que, resumidamente, foram: a escolha equivocada do curso e a descoberta mais tarde, as condições socioeconômicas particulares dos estudantes, aspectos metodológicos e pedagógicos do curso e, ainda, algumas dificuldades na relação professor aluno. Segundo Almeida e Schimiguel (2011), que estudaram as possíveis causas da evasão escolar da Licenciatura em Física de 2001 a 2009 do Centro Federal de Ciência e Tecnologia do Maranhão (IFMA), fatores como a formação e atuação no mercado de trabalho e salário baixo em relação a outras profissões estão entre os motivos.

No tema de evasão e retenção no curso de Física, Júnior, Ostermann e Rezende (2012) analisam os fenômenos de evasão e retenção nos cursos de graduação em Física (bacharelado e licenciatura) oferecidos pela Universidade Federal do Rio Grande do Sul, verificando que estudantes de diferentes origens sociais (em matéria de capitais econômico e cultural), ao entrar em cursos de Física, têm aproximadamente as mesmas chances de obter diploma e estudantes que obtêm diploma ficam retidos aproximadamente por tanto mais tempo quanto pior é sua origem social. Neste ponto, vale mencionar que o estado do Acre teve o rendimento nominal mensal domiciliar per capita de $\mathrm{R} \$ 769,00$ no ano de 2017 segundo dados do IBGE (2017), representando o vigésimo terceiro lugar no ranking dos estados brasileiros neste item. Além disso, a realidade da população do estado e boa parte dos candidatos a pleitear vagas em curso da universidade pública estão inseridos no contexto de possuir baixa renda.

Em geral, vários cursos de graduação de diversas universidades públicas brasileiras apresentam elevados níveis de evasão e retenção (ARRIGO, 2017; VANZ, 2016; SANTOS JUNIOR, 2017), e tais dados devem ser avaliados por meio de vários fatores que podem estar relacionados, como por exemplo, a forma como a matriz curricular do curso está organizada, a escolha precipitada do curso de graduação, abandono por questões de renda familiar para busca de emprego, trancamento de matrícula, a interrupção dos estudos, entre outros.

Dada tal realidade, o presente trabalho buscou investigar e analisar estatisticamente o quantitativo de formandos e evadidos do curso de Licenciatura em Física da UFAC, apresentando um diagnóstico inicial acerca desses acontecimentos. Investigou-se também o tempo de formação, necessário para conclusão do curso, por todos os concluintes desde abertura em 2005, fato que está diretamente relacionado aos índices de repetência dos discentes. Além de analisar pontos como o gênero, faixa etária e naturalidade dos sujeitos da pesquisa, dos professores formados egressos do curso. São estudados estaticamente e discutidos os prováveis motivos que levaram, e continua levando, a evasão e retenção na graduação em Física, bem como evidenciados o grau de importância do curso de formação inicial de professores de Física da UFAC para o estado do Acre.

\section{CAMINHOS METODOLÓGICOS}

A metodologia do trabalho consiste em uma abordagem quantitativa, que segundo Ferreira (2015) trata-se de representar o real através de números. Os dados utilizados nesse trabalho foram coletados no final do segundo semestre de 2018, após a finalização do ingresso dos estudantes aprovados para o curso de Licenciatura em Física pelo SISU (Sistema de Seleção Unificada) do Ministério da Educação, 
para candidatos que participaram do Exame Nacional do Ensino Médio (ENEM), e após a finalização dos processos de evasão e conclusão de curso. Esses foram obtidos dos registros da coordenação do Curso de Licenciatura em Física da UFAC, com um total de 725 estudantes. Desses, 107 ainda estão com matrícula ativa, ou seja, ainda não formaram ou não se evadiram do curso, o que representa $15 \%$ dos dados.

Para análise dos dados foram empregadas duas técnicas estatísticas: a regressão logística simples e a análise de sobrevivência. A primeira visando observar quais os motivos levam os estudantes a evadirem, dentre as registradas nos registros da secretaria, e a segunda como se dá a evasão e a formação ao longo do tempo observado.

\subsection{Caminhos metodológicos: regressão logística}

A regressão logística simples estabelece as relações entre uma variável dependente (variável resposta) e uma ou mais variáveis independentes, para isso, é necessário que a variável dependente seja dicotômica, ou seja, tenha duas possibilidades (respostas) "sim" ou "não" (ZABRISKIE, et al, 2019; BATISTELA, RODRIGUES e BONONI, 2009). Para esse estudo a variável dependente é Evasão e as variáveis independentes são: Matrícula, Ano de Evasão, Ano de Ingresso, Semestre, Data de Nascimento, Idade de Ingresso, Forma de Ingresso e Sexo.

Para execução do modelo de regressão logística simples, transformamos a variável Evasão em binária, ou seja, somente com valores 0 e 1 . Como essa varável apresentava as seguintes formas de evasão, registrada na secretaria do curso como: jubilamento, mobilidade acadêmica, transferência interna, transferência externa, falecimento, desligamento do programa, desistência e formado. Consideramos evadidos todos que não se encaixavam em "formado", atribuindo ao formado o valor 0 e ao evadido o valor 1 .

Na sequência, foi realizado o teste de qui-quadrado $\left(\chi^{2}\right)$ que resulta no $p$-valor permitindo verificar o erro em rejeitar a hipótese de as variáveis serem independentes em relação à variável binária (Evasão). Logo, se para determinada variável independente com uma confiança de $95 \%$ o teste retorna $p \leq 0,05$, então infere-se que essa varável tem relação estatística com a variável dependente (BATISTELA, RODRIGUES e BONONI, 2009). Verificou-se a partir do teste estatístico, que somente as variáveis: Períodos Cursados $(p=0,01)$, Forma de Ingresso $(p=0,01)$ e Sexo $(p=0,02)$, tiveram relação estatística com a variável Evasão.

Após isso, se utilizou o aprendizado de máquina (do inglês Machine Learning) para testar e treinar os dados, esse é um procedimento essencial para verificar a eficiência preditiva de um modelo (neste caso o modelo é a regressão logística). A proporção foi de 70:30, com 70\% destinado para treino de modelo e 30\% para teste, essa proporção é comumente utilizada em técnicas de aprendizado de máquina (AIKEN, HENDERSON e CABALLERO, 2019), os dados de teste e treino são escolhidos aleatoriamente e distintos entre si para garantir a correta previsão do modelo e dos resultados do teste.

Por fim, o modelo é implementado com as variáveis significativamente estatísticas, a precisão da regressão logística foi de $85 \%$. Os dados de teste foram utilizados para verificar a acurácia do método. Esse modelo relaciona variáveis, buscando quais variáveis podem influenciar de alguma maneira em uma variável dependente. Portanto nosso objetivo com esse modelo é identificar quais variáveis podem estar associadas à evasão. 


\subsection{Caminhos metodológicos: análise de sobrevivência}

A análise de sobrevivência é um conjunto de procedimentos estatísticos que estuda o tempo entre eventos de interesse (JUNIOR, SILVEIRA e OSTERMANN, 2011) e analisa a probabilidade desse evento ocorrer em uma faixa de tempo. Essa técnica é amplamente utilizada em Ciências da Saúde, Engenharias, Ciências Sociais e Educação. Em relação a esta última, a análise de sobrevivência tem um grande potencial no estudo de evasão de estudantes do ensino superior, no âmbito nacional (JUNIOR, SILVEIRA e OSTERMANN, 2011) e internacional (TIEBEN, 2020; RODRIGUEZ, POTVIN e KRAMER, 2016). A execução desse modelo se tornou mais descomplicada devido ao tratamento de dados realizado na regressão logística e por sua implementação ser mais simples.

No decorrente trabalho os eventos de interesse são Evasão e Formação e como feito anteriormente, define-se Evadido como 1 e Formado como 0. Para ambos os eventos há dados censurados, que significa que o evento ainda não ocorreu. A censura acontece quando um sujeito não experimenta 0 evento de interesse no período de estudo (RODRIGUEZ, POTVIN e KRAMER, 2016).

Os objetivos com a análise de sobrevivência são estimar o tempo de conclusão dos estudantes na licenciatura em Física da UFAC e comparar a função de sobrevivência, $S_{-} t=P(T>t)$, onde $T$ é o tempo de sobrevivência e t um valor específico, das variáveis estatisticamente significantes.

Utilizamos o método chamado Kaplan-Meier (KAPLAN e MEIER,1958), que se trata de uma estimativa não paramétrica fazendo uso do limite do produto para estimar a função de sobrevivência. A principal vantagem desse método é se basear no cálculo do risco definido a cada fração de tempo em que ocorreu ao menos um evento de interesse (RODRIGUEZ, POTVIN e KRAMER, 2016). Para realizar a comparação entre as curvas de sobrevivência utilizamos o teste Log-Rank que é um teste quiquadrado $\left(\chi^{2}\right)$ entre duas curvas de Kaplan-Meier e a partir do valor $\chi^{2}$ obtemos o $\mathrm{p}$-valor que relaciona se as curvas são estatisticamente significativas (SMITH, WITTMANN e CARTER, 2014).

\section{RESULTADOS E DISCUSSÕES}

A considerável precisão da regressão logística (85\%) e o teste qui-quadrado nos permite inferir que a quantidade de períodos cursados, forma de ingresso e sexo influenciam na evasão dos estudantes do curso de licenciatura em Física da UFAC. A tabela 1 obtida a partir da regressão logística executada, apresenta, para as variáveis estatisticamente significativas, seus coeficientes, erro padrão, valor $Z$ (razão entre o coeficiente e o erro padrão), p-valor, razão de chances (Exp B) e o respectivo intervalo de confiança.

Tabela 1: Resultado da Regressão Logística.

\begin{tabular}{cccccccc}
\hline Variáveis & $\begin{array}{c}\text { Coeficientes } \\
\text { (B) }\end{array}$ & $\begin{array}{c}\text { Erro } \\
\text { padrão }\end{array}$ & Valor Z & $\begin{array}{c}\mathbf{p}- \\
\text { valor }\end{array}$ & $\begin{array}{c}\text { Exp } \\
\text { (B) }\end{array}$ & \multicolumn{2}{c}{$\begin{array}{c}\text { Intervalo de Confiança } \\
\text { (95\%) }\end{array}$} \\
\hline Períodos Cursados & & & & & & $\begin{array}{c}\text { Intervalo } \\
\text { Inferior }\end{array}$ & $\begin{array}{c}\text { Intervalo } \\
\text { Superior }\end{array}$ \\
\hline Forma de Ingresso & 0,32 & 0,03 & 10,1 & 0,00 & 1,37 & 1,29 & 1,46 \\
\hline $\begin{array}{c}\text { Sexo } \\
\text { (masculino/feminino) }\end{array}$ & 0,84 & 0,02 & 3,55 & 0,00 & 1,45 & 1,45 & 3,66 \\
\hline
\end{tabular}

Fonte: Autores. 
O Exp (B) compara a chance de sucesso (ocorrência de um evento) de um grupo em relação a outro a partir da razão entre as probabilidades. Por exemplo, no caso de Exp (B) ter valor maior que uma unidade, se na análise de dois grupos $(X$ e $Y$ ) a razão de chances de o evento evasão ocorrer for de $\operatorname{Exp}(B)=1,13$, significa que a chance de ocorrer um evento para o grupo $X$ é 1,13 vezes maior que para o grupo Y (AMARAL, 2013).

Da tabela 1 infere-se que as variáveis que estão ligadas a evasão são: Períodos Cursados, Forma de Ingresso e Sexo, esse resultado atinge o nosso objetivo para uso desse modelo. Além disso, na coluna Exp (B) se observa que o sexo masculino tem 1,45 mais chances de evadir do que o sexo feminino. Assim como, para cada período cursado a chance de evasão aumenta 32\%.

Em cursos de Física é intuitivo supor que o tempo para concluir o curso é extenso, devido ao nível de dificuldade desta área do conhecimento, entre outros fatores (RISSI, 2013; SILVA, 2013). Nesta perspectiva investigou-se o tempo que os estudantes levaram para finalizar o curso. Observa-se na Figura 2 (a) que a maior quantidade de evasão ocorre entre o $1^{\circ}$ e $6^{\circ}$ períodos. A Figura 2 (b) mostra que a maioria dos discentes conclui o curso no $9^{\circ}$ período, enquanto maior porcentagem de evasão acontece no $4^{\circ}$ período (semestre que iniciam as disciplinas específicas). Nesse semestre é exigido dos alunos maiores habilidades matemáticas, quando comparado com os três anteriores, e capacidade de resolução de problemas com conceitos mais abstratos do ponto de vista Físico.

A taxa de evasão entre o $1^{\circ}$ e $6^{\circ}$ período pode ser explicada pelo impacto causado nos ingressantes que optaram pela licenciatura em Física por ser um dos cursos menos concorridos da UFAC, porém se deparam com uma metodologia que exige do estudante o pensamento crítico, entendimento e desenvolvimento de ideias, diferentemente da metodologia normalmente adotada no Ensino Médio que, muitas vezes, se baseia na repetição e memorização focada na avaliação.

Outro fator que pode contribuir para o alto índice de evasão observado no curso está relacionado aos objetivos dos ingressantes para o curso de física. Rocha, Santos e Pinheiro (2019), apontam, no período de seus estudos, que os licenciandos em Física da UFAC em sua maioria não apresentavam interesse na docência e tinham como objetivo migrar para outros cursos de graduação, em especial as engenharias.

Além disso, o ingressante no curso de Física necessita de conhecimento mínimo em ciências exatas e de acordo com os dados do Sistema de Avaliação da Educação Básica (SAEB), ano base de 2015, onde o estado do Acre obteve o valor de proficiência média em matemática para a $3^{a}$ série do Ensino Médio de 257 (INEP, 2016). Vale destacar que a escala de proficiência em matemática para o $3^{\circ}$ ano do Ensino Médio do SAEB inclui dez níveis: 1 (225-250); 2 (250-275); 3 (275-300); 4 (300-325); 5 (325-350); 6 (350-375); 7 (375-400); 8 (400-425); 9 (425-450); e 10 (450-475). De acordo com a escala descrita pelo SAEB, o Acre está no nível 3 de proficiência em matemática (INEP, 2016), configurando que: o estudante "pode ser capaz de reconhecer as coordenadas de pontos representados em um plano cartesiano localizados no primeiro quadrante" quanto a proficiência sobre "Espaço e forma"; o aluno não possui "itens âncora para esse nível" sobre "Grandezas e medidas"; o discente "pode ser capaz de reconhecer os zeros de uma função dada graficamente" e "também é bem provável que os alunos determinem: o valor de uma função afim, dada sua lei de formação; um resultado utilizando o conceito de progressão aritmética", quanto ao tema números e operações; e o educando "pode ser capaz de associar um gráfico de setores a dados percentuais apresentados textualmente ou em uma tabela" para o "Tratamento de informações". Tais dados corroboram para 
confirmação da defasagem de conteúdos, principalmente de matemática, nos ingressantes no curso de física da UFAC.

Figura 2: (a) Quantidade de alunos por período que evadiram, (b) Porcentagem de alunos de que evadiram e se formaram por período.

(a)
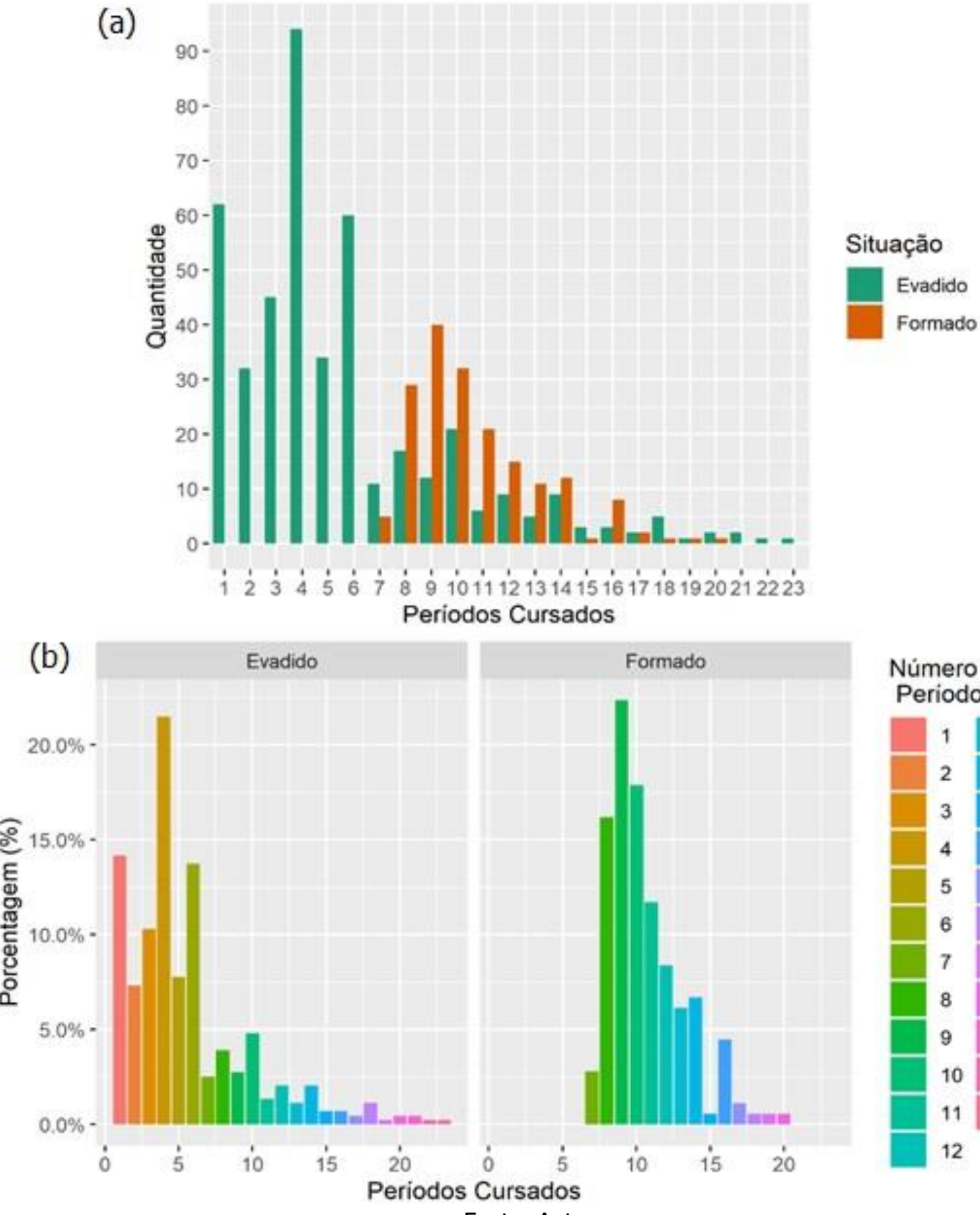

Número de
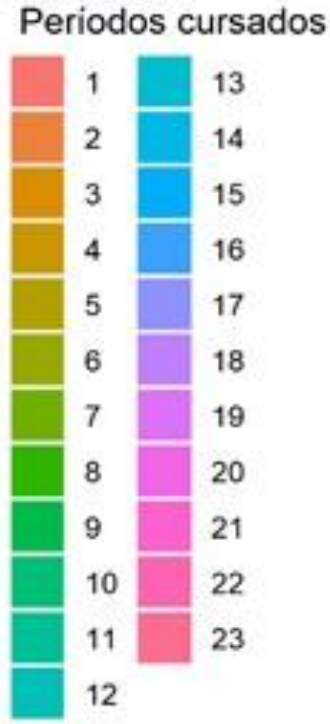

Fonte: Autores.

Verifica-se, na Figura 3, que ao longo do período analisado, nos anos mais recentes o número de estudantes evadidos cresceu, apesar do mercado de trabalho para professores da educação básica não estar saturado, mas o fato de que o salário do professor e a carreira do magistério refletem aspectos negativos a profissão, comparados com a cobrança de conhecimentos de ciências exatas durante a graduação. Situação que pode motivar os graduandos a evadirem do curso. De acordo com a sinopse estatística da educação básica de 2017 , apenas $33 \%$ dos professores do ensino médio têm contrato estável efetivo no estado (INEP, 2017b). 
Figura 3: Número de evadidos e formados por ano.

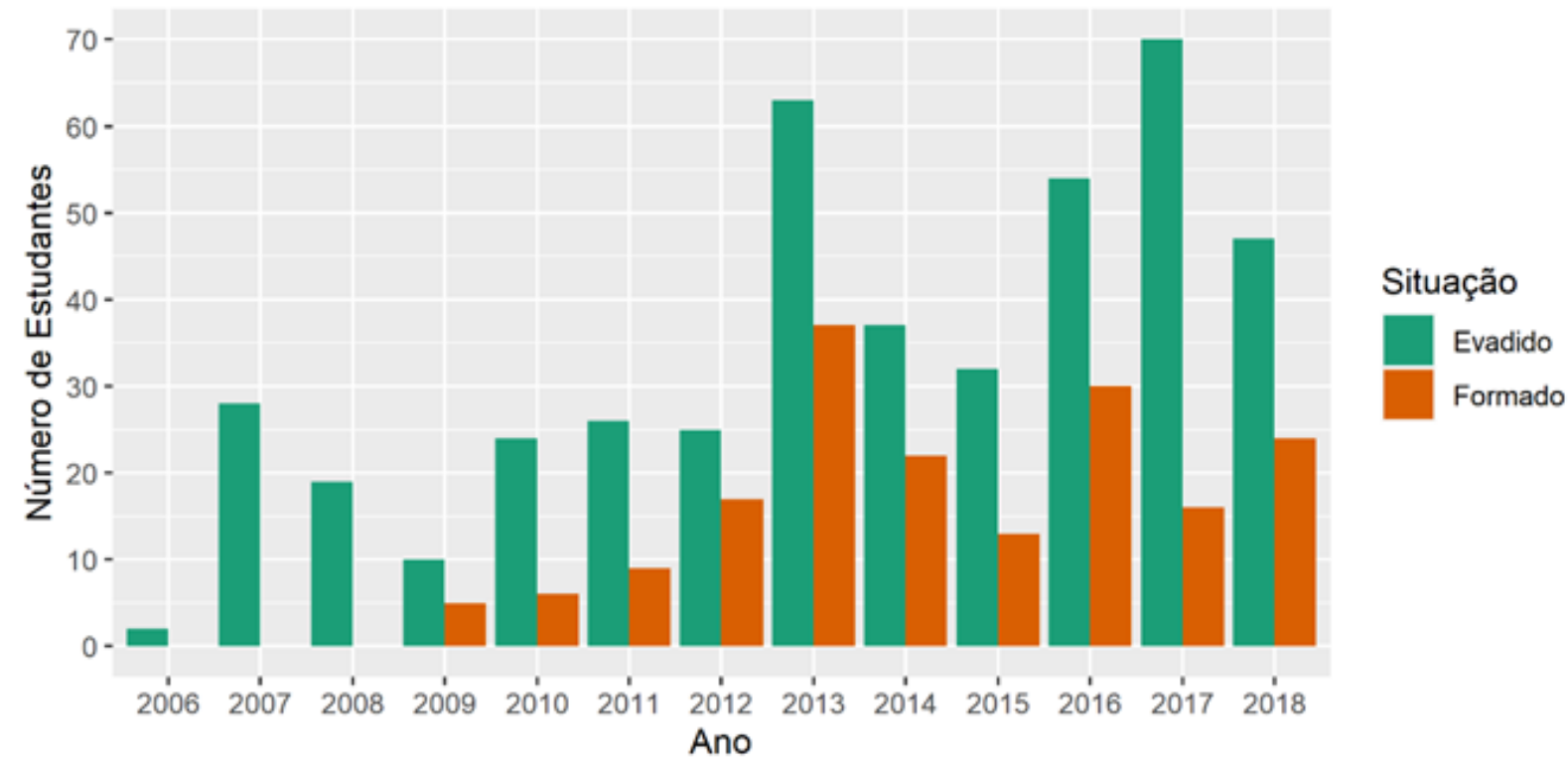

Fonte: Autores.

A Análise de Sobrevivência permite avaliar melhor o comportamento da evasão e da conclusão no tempo de interesse, dessa forma, utilizando essa técnica, será apresentado a seguir o gráfico com as curvas de probabilidade de sobrevivência dos eventos evasão e formação em relação à quantidade de períodos cursados, ou seja, tempo de curso. Nota-se na Figura 4 que após o $6^{\circ}$ semestre ( 3 anos de curso) cerca de $50 \%$ da evasão dos estudantes ainda irá ocorrer e após o 70 período o comportamento da curva é praticamente linear, o que leva a evidência que a decisão de deixar o curso é tomada pelos estudantes após vários semestres, bem como a proporção de evadidos é maior entre $04^{\circ}$ e $6^{\circ}$ períodos (maiores degraus). Ademais, ainda na Figura 4, vê-se que o evento formação ocorre a partir do 70 período e tem maior densidade de evento (tamanho do degrau) entre o $8^{\circ} \mathrm{e}$ $11^{\circ}$ período, apontando que a formação ocorre nessa fração de tempo, após esse intervalo a probabilidade de obtenção de grau reduz e satura a partir do $15^{\circ}$ período, o que representa uma probabilidade relativamente nula de formação.

Figura 4: Probabilidade de ocorrência dos eventos Evasão e Formação.

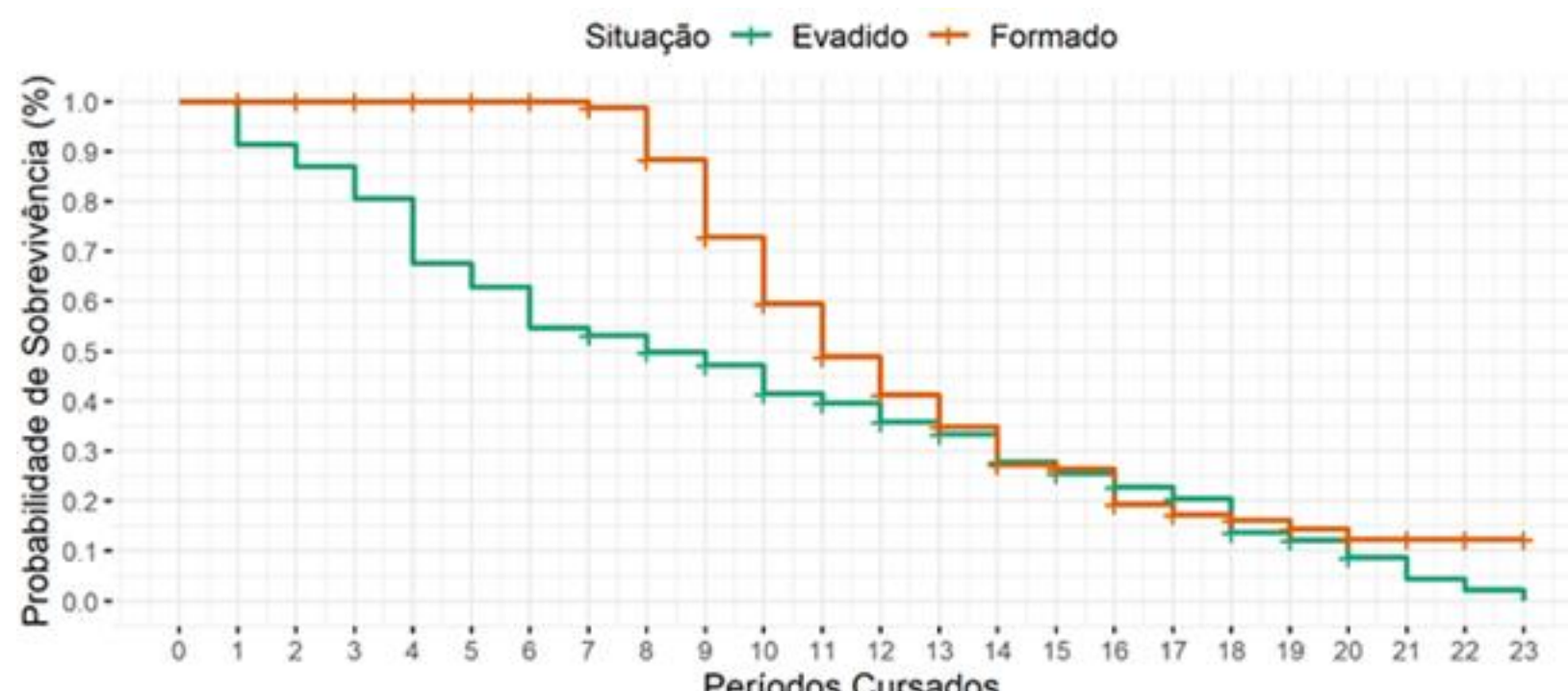

Fonte: Autores. 
Entre 2005 e 2018, o curso formou 179 professores de física. Dentre o total de formados, 59 são mulheres e 120 são homens. Pode-se verificar que o perfil do egresso é predominantemente masculino, $67 \%$ do total, como mostra a Figura 5. A predominância do público masculino no egresso e ingresso do curso, não é uma exclusividade da UFAC, ao contrário, é um padrão que se repete no âmbito nacional (AGRELLO, 2009; LIMA, 2015; ANTENEODO, 2020) e internacional (KALENDER, et al., 2019). Na Figura 5 é perceptível que a taxa de evasão é maior entre os homens, assim como a diferença entre homens e mulheres formados é menor do que a diferença entre os evadidos

Figura 5: Porcentagem de evadidos e formados entre homens e mulheres.

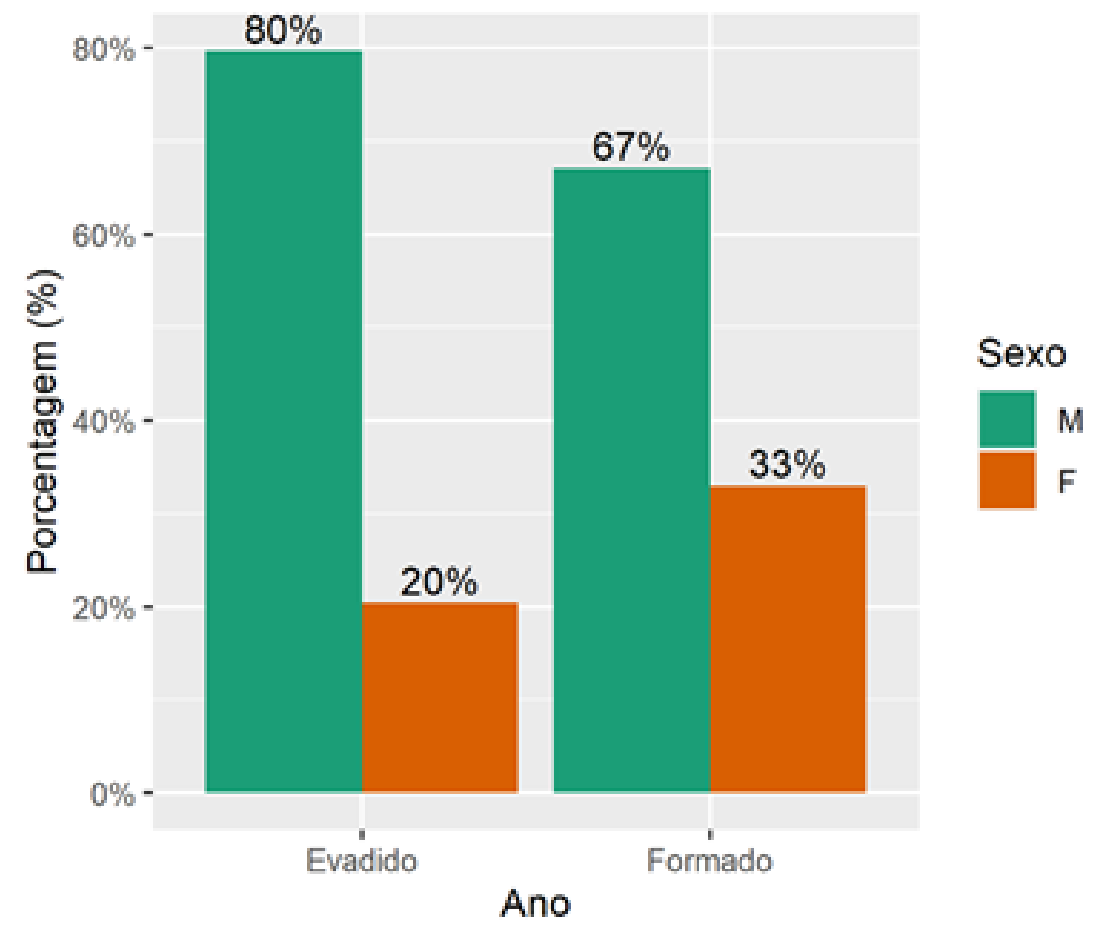

Fonte: Autores.

Além do que, é possível a partir das curvas de análise de sobrevivência (Figura 6(a)), verificar que até o $6^{\circ}$ período a evasão tem comportamento similar para homens e mulheres, já que as curvas estão sobrepostas até este período, do 70 ao $10^{\circ}$ período os homens têm menor probabilidade de "sobrevivência" para evasão, assim como decidem evadir primeiro. Outra informação importante é que metade da evasão dos homens ocorre até o $8^{\circ}$ período, enquanto para as mulheres até o $12^{\circ}$ período. $O$ teste estatístico aponta que a diferença entre as curvas não é estatisticamente significativa com o p-valor de 0,07. Na Figura 6(b), embora as curvas do evento formação estejam sobrepostas até o $9^{\circ}$ período, constata-se que o número de eventos para as mulheres é maior (tamanho do grau), ou seja, a ocorrência do evento formação é ligeiramente maior para as mulheres nessa fração de tempo, com o maior degrau no $9^{\circ}$ período. É somente a partir do $10^{\circ}$ período que a probabilidade de formação para homens se torna sempre maior, porém a densidade do evento tende a saturar (veja a Figura 4). Esse resultado mostra que as mulheres tendem a resistir ao abandono do curso, confirmado pelos trabalhos de Junior, Silveira e Ostermann (2011) e Rodriguez, Potvin e Kramer (2016).

Observa-se, também, que $50 \%$ das mulheres formam no $10^{\circ}$ período, enquanto essa porcentagem só é atingida pelos homens no $12^{\circ}$ período. A diferença entre as curvas é significativa estatisticamente $(p=0,01)$. 
Figura 6: Curvas de análise de sobrevivência para homens e mulheres do evento (a) Evasão e (b) Formação.

(a)

+ Mulheres + Homens

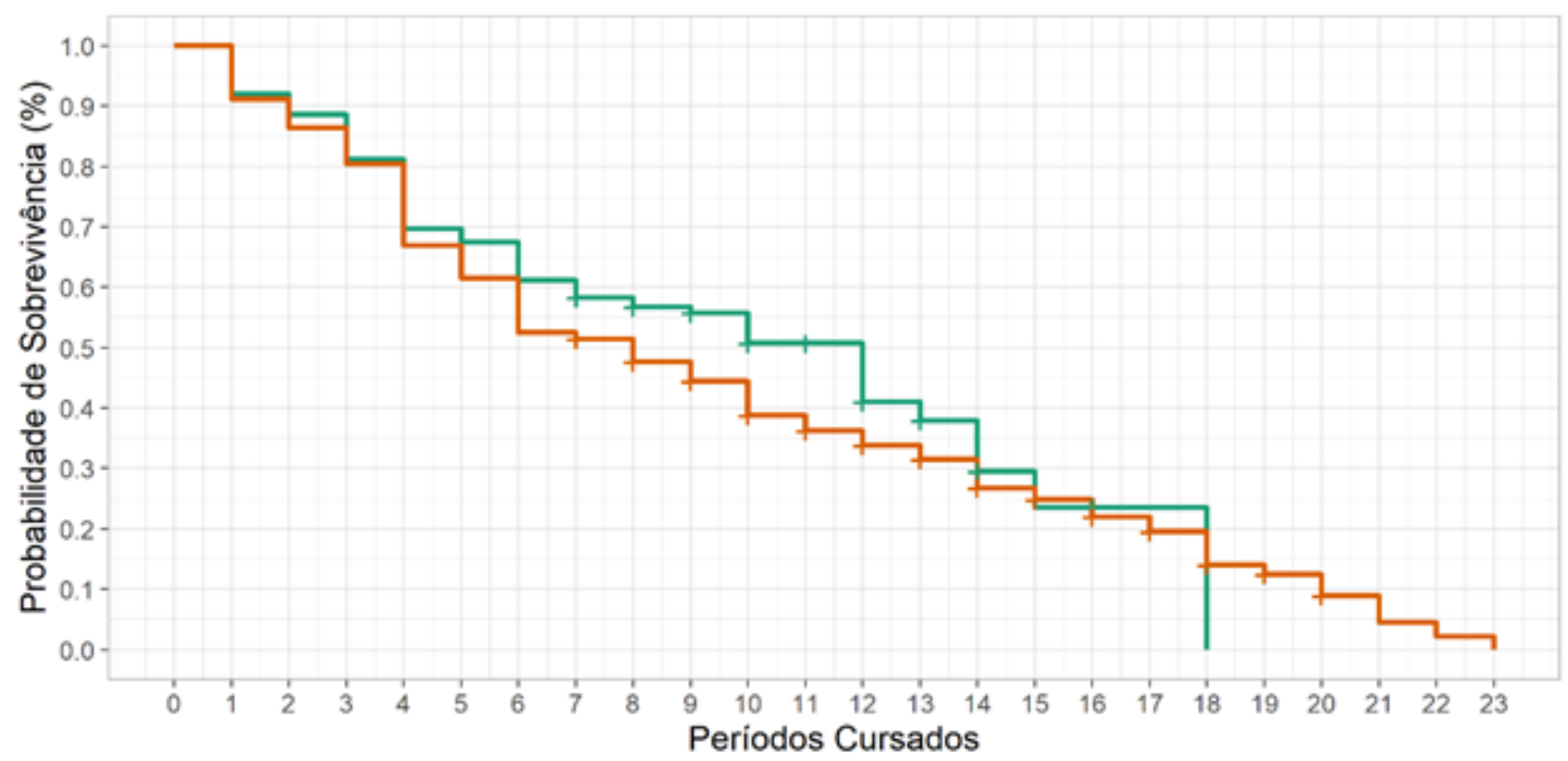

(b)

+ Mulheres + Homens

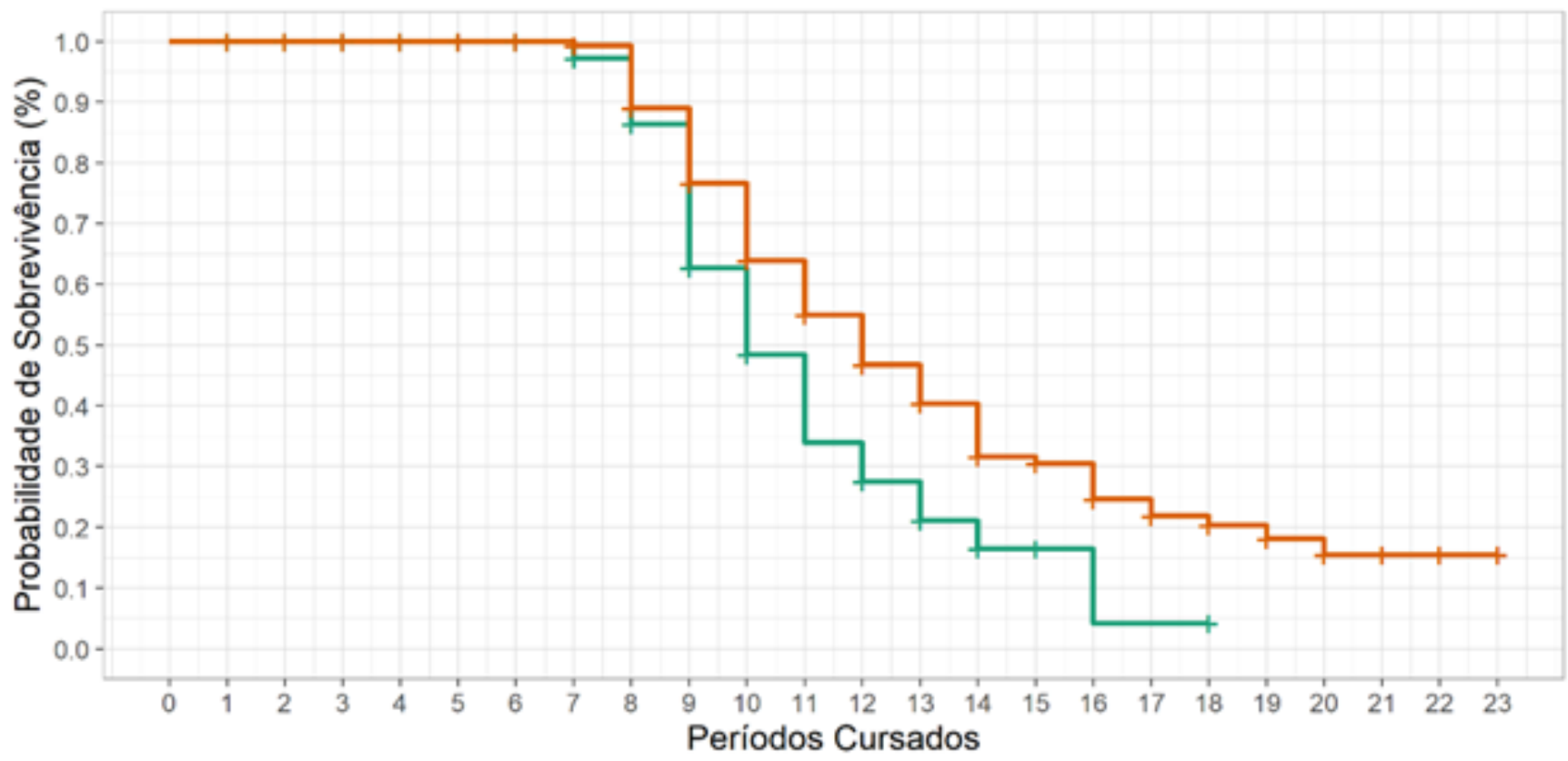

Fonte: Autores.

Outra variável com significância estatística (segundo o teste $\chi^{2}$ realizado para a regressão logística) é a Forma de Ingresso. Na Figura 7, percebe-se que as duas principais formas de ingresso foram o Vestibular e ENEM (atualmente o ingresso é via Sistema de Seleção Unificada - SISU), seguidas por portador de diploma de ensino superior. 
Figura 7: Quantidade e porcentagem de alunos por forma de ingresso.

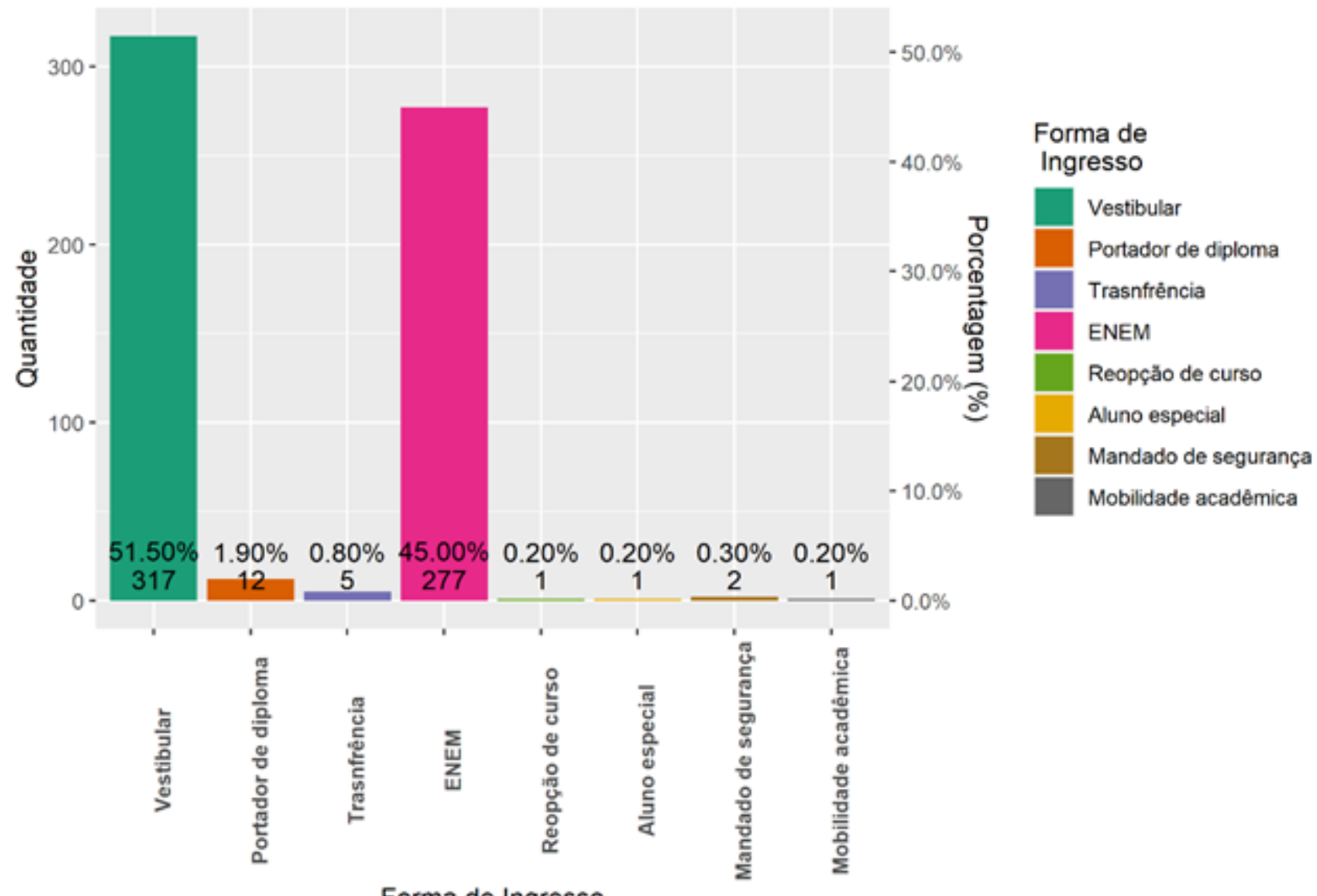

Forma de Ingresso

Fonte: Autores.

As curvas de sobrevivência (Figura 8(a)) expõem que a probabilidade de evasão de estudantes ingressantes pelo ENEM é maior que os ingressantes pelo vestibular, bem como a decisão de evadir é tomada primeiro por estudantes ingressantes via SISU. Ingressos com mandado de segurança, mobilidade acadêmica, aluno especial, transferência e reopção de curso têm probabilidade máxima de evasão. Nos $1^{\circ}$ e $4^{\circ}$ períodos a ocorrência de evasão para os licenciandos ingressantes pelo ENEM é maior, ao passo que para os que prestaram o vestibular essa ocorrência se dá no $6^{\circ}$ período. $A$ taxa de $50 \%$ da evasão para os que utilizaram o ENEM como processo seletivo é atingida no $6^{\circ}$ período, enquanto para os que utilizaram o vestibular é no $11^{\circ}$ período, nota-se, os ingressantes pelo ENEM evadem com maior frequência nos primeiros quatro períodos, enquanto os que ingressaram por meio do vestibular tiveram sua evasão mais acentuada entre o $4^{\circ}$ e $6^{\circ}$ períodos. A constatação de que os estudantes ingressantes via ENEM evadem com maior taxa nos primeiros períodos não é uma particularidade da licenciatura em Física da UFAC, tampouco uma novidade, destaca-se aqui trabalhos relevantes que apontam esse comportamento como o de Li (2016) e de Barros (2014).

A Figura 8(a) destaca que a probabilidade de formação dos ingressantes via vestibular é maior que os ingressantes via SISU, considerando o intervalo do $8^{\circ}$ ao $11^{\circ}$ período, o que era esperado dado que a probabilidade de evasão é maior para licenciandos que utilizaram o ENEM (Figura 8(a)). Além disso, o evento formação ocorre, primeiramente, para a forma de ingresso via SISU no 70 período enquanto que para vestibular no $8^{\circ}$ período. Para a primeira forma de ingresso $50 \%$ dos licenciandos se graduam por volta do $10^{\circ}$ período e para a segunda forma no $12^{\circ}$ período, ou seja, os graduandos ingressantes por meio do ENEM que "sobrevivem" aos primeiros quatro períodos tendem a obter o título com menos semestres cursados. Contudo, a média para obtenção do grau de licenciado está acima do esperado que é de oito períodos (ou quatro anos), para ambas as formas de ingresso. Os 
que ingressam na licenciatura portando um diploma de curso superior, além de ter um comportamento de evasão similar aos ingressantes pelo ENEM (Figura 8(a)) levam 15 períodos para concluir o curso. As formas de ingresso: mandado de segurança, mobilidade acadêmica, aluno especial, transferência e reopção de curso são constantes no tempo, o que significa que o evento formação não ocorre para essas formas de ingresso no período de estudo, como já era esperado. Na parte interna dos gráficos (Figura 8 (a) e (b)) contém tabelas com os p-valores para os pares das curvas de Forma de Ingresso para evasão e formação, respectivamente. Por simplicidade são exibidas as tabelas somente com os pares de curvas estatisticamente significativas. Esse resultado reforça que a forma de ingresso deve ser considerada como uma possível causa da evasão e formação dos licenciandos em Física da UFAC.

Figura 8: Curvas de Análise de Sobrevivência para Formas de Ingresso do evento (a) Evasão e (b) Formação.

(a) + Vestibular + Transferência + Reopção de curso + Mandado de segurança

+ Portador de diploma + ENEM + Aluno especial + mobilidade acadêmica

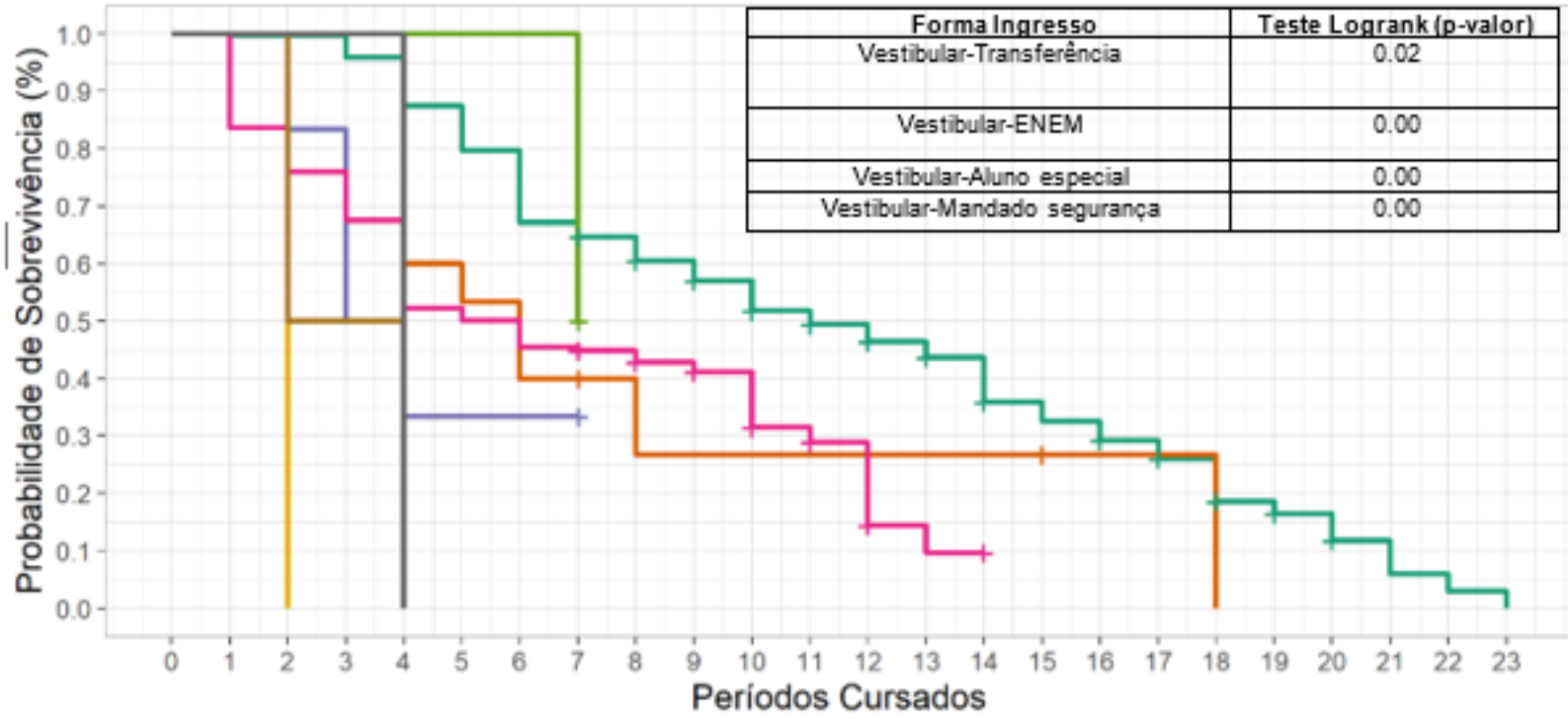

(b) + Vestibular + Transferência + Reopção de curso + Mandado de segurança + Portador de diploma + ENEM + Aluno especial + mobilidade acadêmica

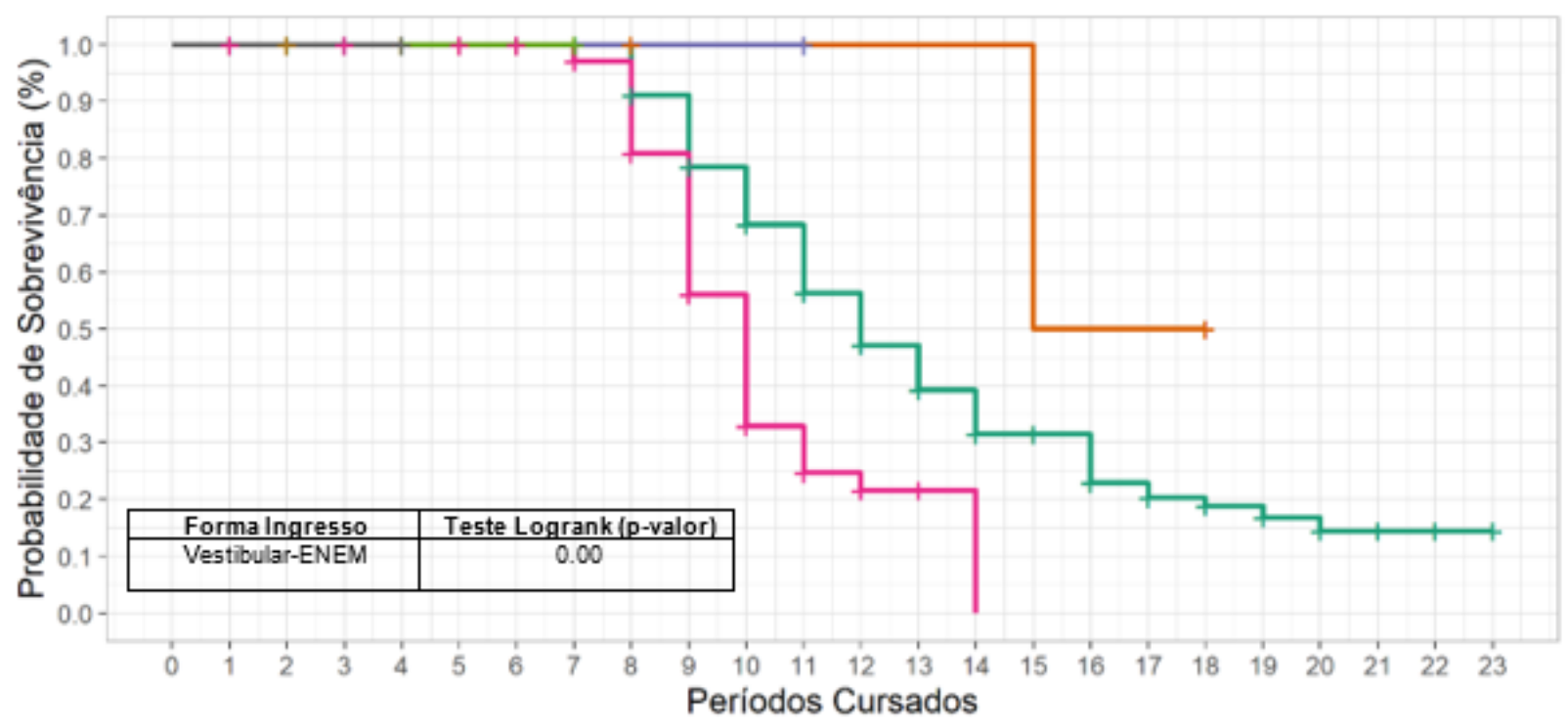


O estudo da análise de sobrevivência foi realizado para as demais variáveis independentes, porém foram omitidas desse trabalho por não apresentar informações expressivas.

Tendo feito o estudo de quais variáveis estão relacionadas com a evasão dos discentes, as análises dos eventos evasão e formação, do seu comportamento ao longo do tempo de estudo (2005 a 2018), considerando os períodos cursados e comparando a função de sobrevivência para as variáveis relacionadas estatisticamente, será apresentado, na sequência, elementos que auxiliaram a traçar o perfil do egresso do curso de licenciatura em Física da UFAC. Para isso, inicialmente, investigou-se a idade com que os acadêmicos se formaram. Para uma melhor síntese dos resultados, analisou-se o total de formados entre os grupos de faixa etária: de 20 a 24 anos, de 25 a 29 anos, de 30 a 34 anos, de 35 à 39 anos, de 40 à 44 anos, de 45 à 49 anos e a partir de 50 anos. Os resultados estão reunidos na Figura 9. Observou-se que grande parte do público de professores de Física formados pela UFAC é jovem, entre 20 e 29 anos, representando 74\% do total. Com um percentual menor de 19\%, a faixa etária entre 30 e 39 anos também aparece. E por último, 7\% representa a quantidade de egressos que concluíram o curso com 40 anos ou mais.

Figura 9: Perfil dos egressos do curso de Licenciatura em Física da UFAC quanto à faixa etária Fonte: Autores.

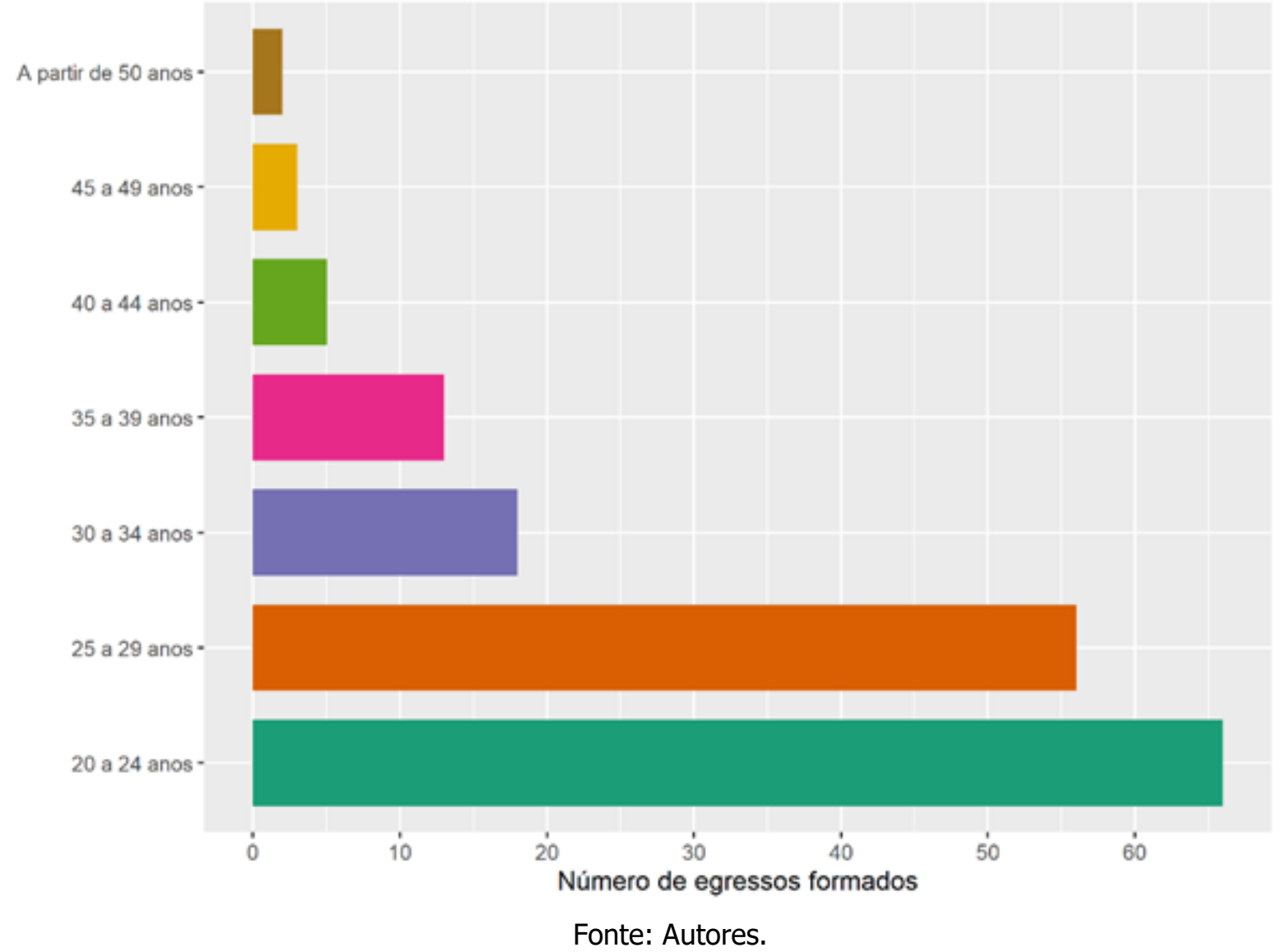

Outro elemento é a nacionalidade e os estados de origem dos ex-alunos do curso, com intuito de estabelecer qual o público-alvo atendido. Constatou-se (Figura 10) que a maioria dos egressos, aproximadamente $90 \%$, é do estado do Acre. Formados naturais dos estados de Rondônia $(1,8 \%)$ e Amazonas $(2,4 \%)$ também apareceram, enquanto que os outros estados brasileiros somaram o total de apenas $5,4 \%$. Vale mencionar que um dos professores formados no curso tem nacionalidade peruana, representando 0,6\%. Mapeado a naturalidade dos licenciados por estado, conforme a Figura 
10(a), apresenta-se o detalhamento do local de nascimento dos egressos restringindo apenas os dados do estado do Acre na Figura 10(b). Verificou-se que a maioria dos egressos nasceu em Rio Branco com 65,8\%, os 34,2\% restantes estão distribuídos entre 13 cidades.

Figura 10: Perfil dos egressos do curso de Licenciatura em Física da UFAC quanto à naturalidade. (a) estão exibidos o percentual de egressos distribuídos entre os estados brasileiros de origem. (b) são indicados especificamente a naturalidade dos ex-alunos nascidos no Acre.

(a)

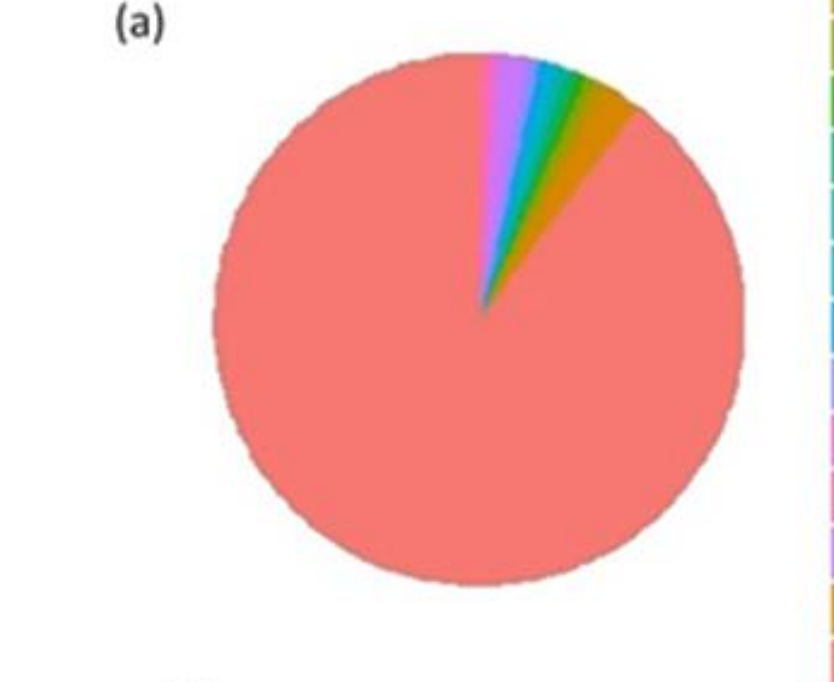

(b)
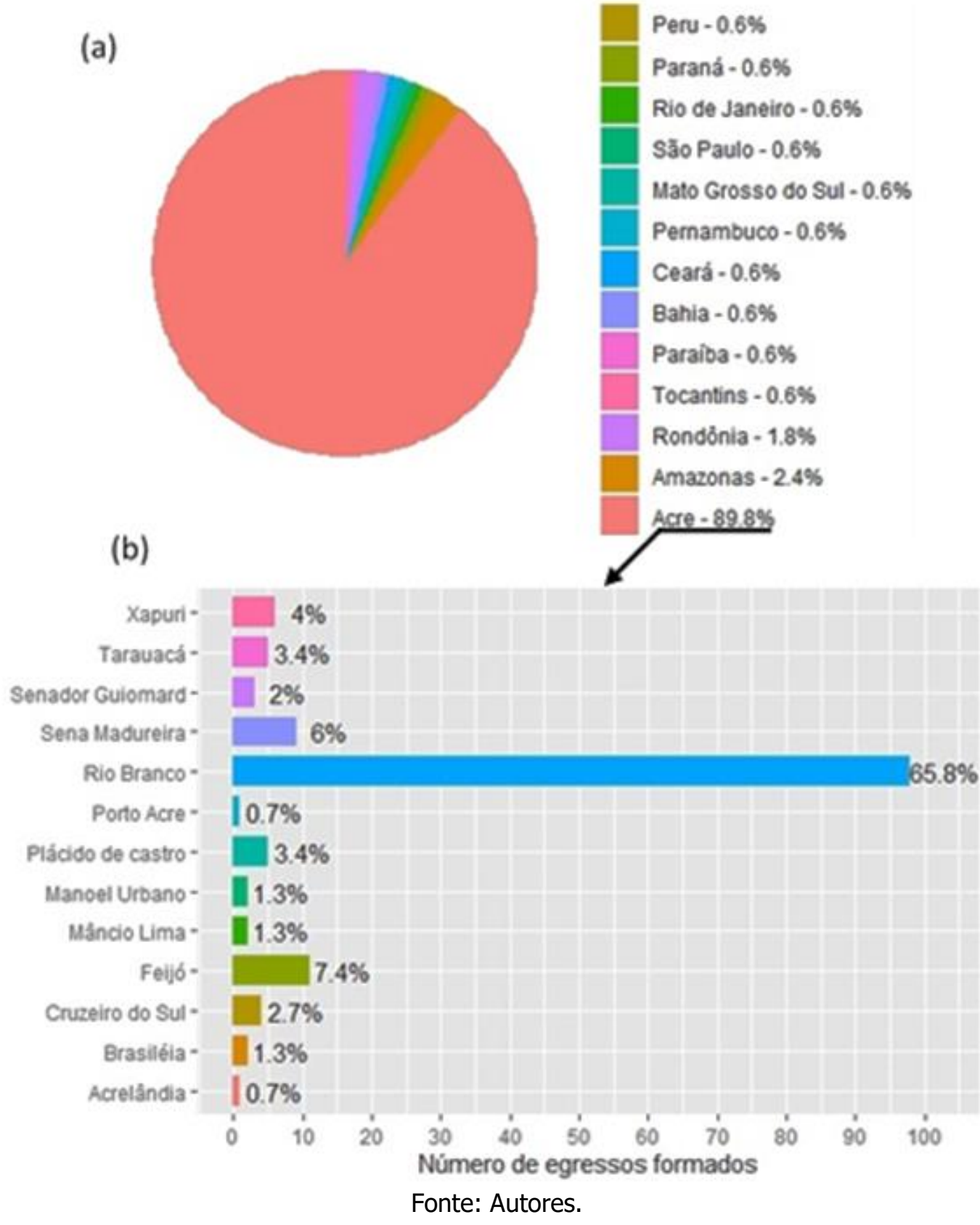
Apesar de o percentual de evadidos do curso não representar o maior índice no estado brasileiro, o resultado observado não é satisfatório, tendo em vista que a média de formados é inferior do que a média de evadidos, isto é, no período de 2005 a 2014 a média de formandos é 14 alunos por turma, enquanto que a média de evadidos é aproximadamente 33 alunos.

Embora os índices de evasão serem consideráveis no curso de Física, o curso é o principal formador de professores para atuarem no componente curricular de Física no ensino básico do estado. Antes da primeira turma de diplomados, existiam apenas 33 professores da componente curricular de física com formação na área (INEP, 2007). Isto mostra que existia um déficit de professores com formação em Física no estado do Acre. Atualmente, esse índice diminuiu, pois, com a formação de 181 professores, o principal destino dos formandos é a escola de educação básica. Desse montante, apenas 7 formandos lecionam em instituições de ensino superior federal no estado. Entretanto, 0 número de formandos precisa crescer para atingir os valores ideais para contemplar a necessidade de professores.

\section{CONCLUSÕES}

O trabalho mostrou que o curso de Física da Universidade Federal do Acre é um importante fonte de formação de professores de Física. A partir da criação do curso, a quantidade de professores de Física no estado aumentou. Vale destacar que os egressos do curso representam grande parte dos educadores que atuam nas escolas estaduais e particulares do Acre. Além disso, o curso de Física da Universidade Federal do Acre é de suma importância para a sociedade acreana, pois a maioria dos formandos estão trabalhando nas salas de aula da educação básica.

Entretanto, um problema que aflige todos os cursos de graduação também foi evidenciado no trabalho, a evasão escolar do curso de licenciatura em Física da UFAC foi de $60 \%$ até o início do primeiro semestre de 2018. Verificou-se através da regressão logística que as principais causas para essa evasão são quantidade de períodos cursados, forma de ingresso e sexo. Além disso, destacouse neste trabalho, por meio da análise de sobrevivência, que os homens tendem a deixar o curso primeiro que as mulheres, assim como os ingressantes pelo SISU evadem primeiro que os ingressantes via vestibular e que a formação dos licenciandos ocorre entre 070 e $11^{\circ}$ períodos, enquanto a evasão ocorre já no 10 período.

Quanto ao perfil dos diplomados pelo curso, pode-se levantar algumas características iniciais, como o fato da maioria ser do sexo masculino (67\%) e de faixa etária entre 20 e 29, sendo a maior parte desses naturais do Acre. Contudo, em trabalhos futuros, é possível reunir mais elementos do perfil dos egressos e, esses, podem ser importantes dados para uma análise mais profunda sobre a evasão e diplomação dos licenciandos em Física da UFAC. Assim como auxiliar para inferir o perfil dos evadidos, pois, identificando esse perfil com antecedência é possível executar medidas para atenuar a evasão desse grupo.

De maneira geral o trabalho apresenta um panorama inicial do curso de licenciatura em física da UFAC e, a partir das análises estatísticas, discute a evasão dos licenciandos em Física da UFAC e os motivos que podem estar relacionados esse evento. Concomitantemente, por ser o primeiro a analisar a evasão na Licenciatura em Física da UFAC, abre espaço para outros trabalhos com mais dados para uma análise mais abrangente da evasão e também da formação desses licenciandos. 


\section{REFERÊNCIAS}

AGRELLO, Deise Amaro; GARG, Reva. Mulheres na física: poder e preconceito nos países em desenvolvimento. Revista Brasileira de Ensino de Física, v. 31, n. 1, p. 1305-1/1305-6, 2009.

AIKEN, John M; HENDERSON, Rachel; CABALLERO, Marcos D. Modeling student pathways in a physics bachelor's degree program. Physical Review Physics Education Research, v. 15, n. 1, p. 0101281- 0101287, 2019.

ALMEIDA, João Batista; SCHIMIGUEL, Juliano. Avaliação sobre as causas da evasão escolar no ensino superior: estudo de caso no curso de licenciatura em Física no Instituto Federal do Maranhão. REnCiMa, v. 2, n. 2, p. 167-178, 2011.

AMARAL, Ernesto Friedrich de Lima. Análise de Regressão Logística. Disponível em: http://www.ernestoamaral.com/docs/dcp046-141/Aula33.pdf. Acesso em: 05 jan 2021.

ANTENEODO, Celia, et al. Brazilian physicists community diversity, equity, and inclusion: A first diagnostic. Physical Review Physics Education Research, v. 16, n. 1, p. 0101361- 01013613, 2020.

ARRIGO, Viviane; SOUZA, Miriam Cristina Covre de; BROIETTI, Fabiele Cristiane Dias. Elementos caracterizadores de ingresso e evasão em um curso de licenciatura em Química. ACTIO: Docência em Ciências, Curitiba, v. 2, n. 1, p. 243-262, 2017.

BARROS, Aparecida da Silva Xavier. Vestibular e Enem: um debate contemporâneo. Ensaio: Avaliação e Políticas Públicas em Educação, v. 22, n. 85, p. 1057-1090, 2014.

LI, Denise Leyi. O novo ENEM e a plataforma Sisu: efeitos sobre a migração e a evasão estudantil. Dissertação (Mestrado em Economia) - Faculdade de Economia, Administração e Contabilidade da Universidade de São Paulo. São Paulo, p. 108. 2016.

BASTISTELA, Gislaine Cristina; RODRIGUES, Sergio Augusto; BONONI, Júlia T. Carrer Martinelli. Estudo sobre a evasão escolar usando regressão logística: análise dos alunos do curso de administração da fundação educacional de Ituverava. Tékhne $\varepsilon$ Lógos, v.1, n. 1, p.54-67, 2009.

DAVOK, Delsi Fries; BERNARD, Rosilane Pontes. Avaliação dos índices de evasão nos cursos de graduação da Universidade do Estado de Santa Catarina - UDESC. Avaliação, Campinas; Sorocaba, SP, v. 21, n. 2, p. 503-521, 2016.

FERREIRA, Carlos Augusto Lima. Pesquisa quantitativa e qualitativa: perspectivas para o campo da educação. Revista Mosaico, v. 8, n. 2, p. 173-182, 2015.

GATTI, Bernardete. Estudos quantitativos em educação. Educação e Pesquisa, São Paulo, v.30, n.1, p. 11-30, 2004.

IBGE, Instituto Brasileiro de Geografia e estatística. CENSO DEMOGRÁFICO - 2017. IBGE. Disponível em: https://cidades.ibge.gov.br/brasil/ac/panorama. Acesso: 18 jun. 2018.

IFAC, Instituto Federal do Acre. Plano de Desenvolvimento Institucional: PDI 2009-2013, 2009. IFAC. Disponível em: http://portal.ifac.edu.br/pdi.html. Acesso: 17 jun. 2018.

IFAC, Instituto Federal do Acre. Plano de Desenvolvimento Institucional: PDI 2014-2018, 2014. IFAC. Disponível em: http://portal.ifac.edu.br/pdi.html. Acesso: 17 jun. 2018. 
IFAC, Instituto Federal do Acre. Histórico IFAC, 2016. IFAC. Disponível em: http://portal.ifac.edu.br/historico.html. Acesso: 17 jun. 2018.

INEP, Instituto Nacional de Estudos e Pesquisas Educacionais Anísio Teixeira. Censo Escolar da Educação Básica de 2007. INEP. Brasília: Inep, 2007. Disponível em: http://portal.mec.gov.br/plano-nacional-de-formacao-de-professores/censo-do-professor. Acesso em: 3 ago. 2018.

INEP, Instituto Nacional de Estudos e Pesquisas Educacionais Anísio Teixeira. Escala de Proficiência, 2013. INEP. Disponível em: http://download.inep.gov.br/educacao_basica/prova_brasil_saeb/escala/escala_proficiencia/2013/es cala_ensino_medio_2013.pdf. Acesso em: 3 ago. 2018.

INEP, Instituto Nacional de Estudos e Pesquisas Educacionais Anísio Teixeira. SAEB, SISTEMA DE AVALIAÇÃO DA EDUCAÇÃO BÁSICA. Edição 2015 - Resultados. Brasília-DF, Setembro de 2016. INEP. Disponível

em: http://download.inep.gov.br/educacao_basica/saeb/aneb_anresc/resultados/resumo_dos_resultado s_saeb_2015.pdf. Acesso em: 3 ago. 2018.

INEP, Instituto Nacional de Estudos e Pesquisas Educacionais Anísio Teixeira. Censo Escolar da Educação Básica - 2016 Notas Estatísticas. Brasília-DF, Fevereiro de 2017a. INEP. Disponível em:http://download.inep.gov.br/educacao_basica/censo_escolar/notas_estatisticas/2017/notas_est atisticas_censo_escolar_da_educacao_basica_2016.pdf. Acesso: janeiro de 2020.

INEP, Instituto Nacional de Estudos de Pesquisas Educacionais Anísio Teixeira. Sinopse Estatística da Educação Básica 2017b. Brasília: Inep, 2018. INEP. Disponível em: http://portal.inep.gov.br/basicacenso-escolar-sinopse-sinopse. Acesso em: 3 de ago. 2018

INEP, Instituto Nacional de Estudos e Pesquisas Educacionais Anísio Teixeira. Censo Escolar da Educação Básica - 2018 Notas Estatísticas. Brasília-DF, Fevereiro de 2019. INEP. Disponível em:http://download.inep.gov.br/educacao_basica/censo_escolar/notas_estatisticas/2018/notas_est atisticas_censo_escolar_2018.pdf. Acesso: janeiro de 2020.

JÚNIOR, Paulo Lima; OSTERMANN, Fernanda; REZENDE, Flávia. Análise dos condicionantes sociais da evasão e retenção em cursos de graduação em Física à luz da sociologia de Bourdieu. Revista Brasileira de Pesquisa em Educação em Ciências, v. 12, n. 1, p. 37-60, 2012.

KALENDER, Z. Yasemin, et al. Gendered patterns in the construction of physics identity from motivational factors. Physical Review Physics Education Research, v. 15, n. 2, p. 020119102011919, 2019.

KAPLAN, Edward L.; MEIER, Paul. Nonparametric estimation from incomplete observations. Journal of the American statistical association, v. 53, n. 282, p. 457-481, 1958.

LIMA, Betina Stefanello; BRAGA, Maria Lúcia de Santana; TAVARES, Isabel. Participação das mulheres nas ciências e tecnologias: entre espaços ocupados e lacunas. GÊNERO, Niterói, v.16, n.1, p. 11 $31,2015$.

MEC, Ministério de Educação. MEC lança Política Nacional de Formação de Professores com Residência Pedagógica, 2018. MEC. Disponível em: http://portal.mec.gov.br/ultimas-noticias/211218175739/55921-mec-lanca-politica-nacional-de-formacao-de-professores-com-80-mil-vagas-pararesidencia-pedagogica-em-2018. Acesso: 17 jun. 2018. 
PEREIRA DE ATAÍDE, Jair Stefanini; LIMA, Lourivaldo Mota; ALVES, Edvaldo de Oliveira. A repetência e o abandono escolar no curso de licenciatura em física: um estudo de caso. Physicae, v. 6, n. 6, p. 21-32, 2006.

RISSI, Marinalva Calabrez; MARCONDES, Martha Aparecida Santana (organizadoras). Reflexão sobre a reprovação, retenção e evasão na UEL: retenção em 2010, reprovação 2010 a 2012 e evasão 2003 a 2012 nos cursos de graduação. Londrina: Universidade Estadual de Londrina, 2013.

ROCHA, Ynara Gabrielly Magalhães; BIANCA, Martins Santos; PINHEIRO, Antônio Romero da Costa. Percepções dos alunos de Física da UFAC sobre o curso. Debates em Educação, v. 11, n. 25, p. 107-122, 2019.

RODRIGUEZ, Idaykis; POTVIN, Geoff; KRAMER, Laird H. How gender and reformed introductory physics impacts student success in advanced physics courses and continuation in the physics major. Physical Review Physics Education Research, v.12, n. 2, p. 0201181- 0201189, 2016.

SANTOS JUNIOR, José da Silva; REAL, Giselle Cristina Martins. A evasão na educação superior: o estado da arte das pesquisas no Brasil a partir de 1990. Avaliação, Campinas; Sorocaba, SP, v. 22, n. 2, p.385-402, 2017.

SILVA, Glauco Peres da. Análise de Evasão no Ensino Superior: Uma Proposta de Diagnóstico de Seus Determinantes. Avaliação (UNICAMP), v. 18, p. 311-333, 2013.

SMITH, Trevor; WITTMANN, Michael; CARTER, Tom. Applying model analysis to a resource-based analysis of the Force and Motion Conceptual Evaluation. Physical Review Physics Education Research, v. 10, n. 2, p. $0201021-02010217,2014$.

TIEBEN, Nicole. Non-completion, Transfer, and Dropout of Traditional and Non-traditional Students in Germany. Research in Higher Education, v. 61, p. 117-141, 2020.

UFAC, Universidade Federal do Acre. Plano de Desenvolvimento Institucional - PDI 20112014: A UFAC construindo o futuro no cenário da Amazônia Ocidental. Rio Branco: EDUFAC, 2011.

UFAC, Universidade Federal do Acre. Regimento Geral da Universidade Federal do Acre. Rio Branco: Ufac, 2013.

VANZ, Samile Andrea de Souza; PEREIRA, Patrícia Mallmann Souto; FERREIRA, Glória Isabel Sattamini; MACHADO, Geraldo Ribas. Evasão e retenção no curso de Biblioteconomia da UFRGS. Avaliação, Campinas; Sorocaba, SP, v. 21, n. 2, p. 541-568, 2016.

ZABRISKIE, Cabot, et al. Using machine learning to predict physics course outcomes. Physical Review Physics Education Research, v. 15, n. 2, p. 0201201-02012018, 2019.

Submissão: 24/11/2020

Aceito: 06/01/2021 